International Journal of Instruction e-ISSN: 1308-1470 • www.e-iji.net
October $2018 \bullet$ Vol.11, No.4

p-ISSN: 1694-609X

pp. 207-222

Received: 26/02/2018

Revision: 04/06/2018

Accepted: 09/06/2018

\title{
Teacher-vs. Peer-mediated Learning of Grammar through Dynamic Assessment: A Sociocultural Perspective
}

\section{Farid Khanahmadi}

PhD, University of Urmia, Iran, khanahmadi.farid@gmail.com

\section{Mehdi Sarkhosh}

Asst. Prof., University of Urmia, Iran, mdsarkhosh@gmail.com

\begin{abstract}
Mediation in general, and teacher and peer-mediation in particular, whose genesis are Vygotsky's sociocultural and Feuerstein's mediated learning experience theories, is a novel approach aimed at scaffolding low level learners by experienced instructors or peers. The main objectives of the present study, however, were to investigate the effects of teacher and peer-mediation on EFL learners' grammar learning (active vs. passive voice) at pre-intermediate level. In addition, the focus was on the effectiveness of the two strategies of mediation on grammar learning and retention. To this end, a sample of $45 \mathrm{EFL}$ learners within the age range of 14 to 19 was selected from among 68 pre-intermediate learners of a private language institute in Khoy, Iran. A homogeneity test, pretest, immediate and delayed posttests were used as data collection tools. The results revealed that teacher-mediation was more effective than peer-mediation and traditional and/or static assessment in improving the learning of active vs. passive voice statements in the short and long-run.
\end{abstract}

Keywords: peer-mediation, teacher-mediation, grammar learning, active voice, passive voice

\section{INTRODUCTION}

Teaching and classrooms are usually connected with concepts such as theory and practice. Therefore, as Williams and Burden (1997) note, not only should teachers be aware of the degree of match and mismatch between their "espoused" theories and their "theories-in action", they also need to know the many different ways by which they can influence the learning process in their classrooms through "words" and "actions". Some of these ways, according to Williams and Burden, would be "teaching learners how to learn, boosting their confidence, motivating, displaying a personal interest, enhancing self-esteem, and organizing an appropriate learning environment" (p. 65).

It seems that each of these ways belongs to different schools of thought in psychology, including behaviourism, cognitive approaches and humanistic approaches among them.

Citation: Khanahmadi, F., \& Sarkhosh, M. (2018). Teacher-vs. Peer-mediated Learning of Grammar through Dynamic Assessment: A Sociocultural Perspective. International Journal of Instruction, 11(4), 207-222. https://doi.org/10.12973/iji.2018.11414a 
Cognitive approaches to psychology lay weight on learners' cognitive involvement in learning and humanistic approaches lay stress on whole-person involvement in learning. Therefore, it seems that none of the mentioned approaches taps into the social facets of learning whilst as Halliday (1973) argues, language is fundamentally a social phenomenon; likewise, it needs to be learned in an appropriate social context through interaction. Consequently, we need a different approach that not only encompasses the insights of the previous psychological approaches, but also pays a close attention to social interactions, i.e., social interactionism. Unfortunately, so far, this important aspect of learning has appropriately not received the level of attention it deserves in Iranian EFL settings. It should be noted that the most important concept to both Vygotskian and Feuersteinian psychology and social interactionists is mediation, which refers to the role that others play in children's lives. To be more exact, other people who are more knowledgeable and experienced than the children, can act as mediators and help them move slightly beyond their current level of knowledge. Mediation to Vygotsky and his followers, a concept that has had crucial part in all social interactionist theories, refers to the application and use of 'tools'. Indeed, it refers to anything that can be used to solve problems or achieve a goal. The most important of these tools according to Kozulin (1990) is symbolic language (cited in Williams \& Burden, 1997).

Vygotsky proposed the concept as zone of proximal development (ZPD), which refers to the level of knowledge and skill beyond that of the current level of a child when mediated by another person. It is in fact the distance between child's actual level of development and his/her potential level of development when mediated appropriately. For these psychologists, what is of particular significance is the use of mediational language that helps learners move into and through their ZPD. Peer-mediation and teacher-mediation as two types of mediation were the focus of the present study. It is evident that teacher mediation came to the scene with the emergence of scaffolding and mediation, but the concept of peer-mediation as a newly developed concept (Shamir, 2005) was introduced following studies on the role of mother-child mediation and the nature of children's cognitive modifiability (Tzuriel, 1999).

As stated above, scaffolding in general, and teacher and peer-mediation in particular have been studied from the heydays of sociocultural theory (SCT) up to the present time by different scholars. There are still some aspects of mediation, especially peermediation which have been neglected to a large extent. Thus, owing to the mentioned gaps and a dearth of adequate empirical studies into the role that mediation/mediated learning experience can play in language learning, especially when it comes to grammar, this study intended to apply a dynamic assessment intervention. That is to say, a dialogic mediation between the examiner and the examinee (mediator-learner interaction), which includes hints, explanations, suggestions, prompts, and more importantly leading questions, examples, and demonstrations offered by the tester to help students develop their English language abilities and become effective and independent learners. Then, based on the aims of the present study, the following research questions were formulated: 
RQ1: Is there any significant difference in the relative effects of teacher-mediation and peer-mediation on pre-intermediate English learners' use of target forms (active vs. passive voices) in the short-run?

RQ2: Is there any significant difference in the relative effects of teacher-mediation and peer-mediation on pre-intermediate English learners' use of target forms (active vs. passive voices) in the long-run?

\section{Literature review}

To begin with, it should be noted that despite the fact that the genesis of dynamic assessment was Vygotsky's SCT of mind and his notion of ZPD, the word "dynamic assessment" was not used directly by Vygotsky himself; rather it was his colleague Luria, who first coined the term dynamic assessment (DA), a concept that was popularized by special educator Reuven Feuerstein (Poehner, 2007). DA cavaliers are mainly Binet, Vygotsky, and Feuerstein, respectively, whose work led assessment to a rapidly growing testing renaissance. However, Poehner (2008) observes that a historical precedent to DA can be found in the Socratic dialogues described by Plato. Through Socratic method, that is, clever questioning and quick insightful responses, Socrates succeeds time and helps his interlocutors to notice the flaws in certain ideas whilst simultaneously in a collaborative fashion, constructs a new perspective. As a prime example of such a dialogue, Poehner refers to Phaedrus, where Socrates draws on a series of leading questions and suggestions to aid the title character identify certain logical problems in a speech he had been admiring, and whereby sets the scene to launch off in new directions of thinking on the topic. In this process, as puts Poehner, the Socratic dialogue involves, to some extent, simultaneous assessment and instruction.

DA as an interactive test-intervene-retest procedure is a model of psychological and psycho-educational assessment, which is highly appealing to practicing psychologists (Haywood \& Lidz, 2007). It has somehow found its way to psychological, neurological, speech/language, and educational settings. Poehner (2008) also observes that DA arises from an ontological perspective on human abilities, which Russian psychologist Vygotsky developed more than 80 years ago. Thus, as Poehner claimed, social milieu is the main element in cognitive development in which individual's cooperation and involvement in different activities is mediated by another person (mediator) or even by other means. To put it another way, in Vygotskian SCT, man's cognition is studied within its social context (Azabdaftari, 2015). Very simply, cognitive and educational development are both directed and affected by social environment. For Karpove (2008), DA makes it possible to evaluate learners' learning potential; however, he is of the opinion that some of the DA techniques do not evaluate kinds of learning potential, and his rationale behind his assertion is Haywood and Lidz's (2007) sound proclamation to the effect that the concept of learning potential is not well defined so that different DA techniques evaluate different potentials. Poehner (2008) asserts that the ZPD is Vygotsky's solution to overcome the instruction-assessment dualism. According to Lantolf and Thorne (2006), the ZPD has attracted educators and psychologists for a variety of reasons, including notion of assisted performance, which has been the incentive behind much of the interest in Vygotsky's research and the ZPD. In contrast to 
the traditional tests and measures, the ZPD asserts that what one can do today with help is indicative of what one will be ready to do independently without any assistance in the future.

For Poehner and Lantolf (2003), central to the ZPD, and the core concept of Vygotsky's theory of mind, is mediation. They assert that socially and culturally derived forms of thinking are of higher forms which emerge as a consequence of our interaction with other individuals and with physical and symbolic artifacts (e.g., books, paper and pencil, computers, diagrams, numbers and language, etc.). They believe that these higher forms are constructed by others in different places and at different times. Thus, in this way, according to Poehner and Lantolf (2003), our relationship to the world is not direct; rather it is mediated. Depending on the level of support received by a child on a task, varying outcomes can be expected (Murphy, 2008). "Performance at the functional level is expected with minimal or no support as opposed to optimal performance when supported in a task" (Suizzo, 2000, cited in Murphy, 2008, p. 194). Vygotsky's formulation of the ZPD was based on his observation that schooling frequently enhanced the IQ score of some but not all children (Van der Veer \& Valsiner, 1991, cited in Poehner \& Lantolf, 2003). Importantly, it was the children who entered school with low scores who most often improved over time, while those with already high scores generally did not show much improvement. Vygotsky, according to Poehner and Lantolf (2003), reasoned that this differential effect of schooling was a consequence of the fact that children with high IQs had already traversed the distance between their actual and potential development (relative to what the school curriculum concretely offered) prior to entering school, but that their low IQ classmates still had room for development to occur.

In his work on the problem of age in development, Vygotsky argues against the general view that independent problem solving is the only valid indication of mental functioning, suggesting that this reveals only part of a person's mental abilities - his or her actual development level (Lantolf \& Poehner, 2003; Lantolf \& Thorn, 2006). To Vygotsky, responsiveness to assistance is an indispensable feature for understanding cognitive ability because it provides an insight into the person's future development. That is, what the individual is able to do today with assistance, she/he is able to do tomorrow by himself. Potential development varies independently of actual development, namely, the latter, in and of itself, cannot be used to predict the former. Moreover, the former is not a prior prediction but is derived from concrete activity mediated by others or cultural artifacts" (Poehner \& Lantolf, 2003).

As mentioned before, this study focused on two types of mediation (teacher vs. peermediation); these mediation strategies have been studied from different angles. For instance, Ableeva (2008) conducted a test -teacher intervention-retest model of study focusing primarily on the effects of DA on developing L2 French students' listening comprehension at university level where participants achieved a better comprehension with mediator's guidance. Through mediation, Ableeva was able to uncover the source of comprehension problems that in one case hinged on a single lexical item and in another on cultural knowledge, which revealed that learners' abilities were more 
developed than one would have surmised from unmediated performance. Hidri (2014), in a study, tried to address the need to investigate and improve current assessments of listening comprehension of university EFL learners; those that adopt a traditional approach where learners listen as usual to an audio recording of a spoken interaction and then are required to answer some written questions independently. He proposed and explored a DA of a listening test, which involved mediation and meaning negotiation as the learners tried to respond to the listening comprehension tasks. Based on qualitative data analysis, it was revealed that DA-based assessment outperformed the static one in providing better insights into learners' cognitive and meta-cognitive processes; however, as claims Hidri, raters were doubtful about the value of and processes involved in DA because they were not familiar with it.

The realization of children's learning potential, according to the theories of Vygotsky and Feuerstein, is conditioned by exposure to experiences in social interaction with other people, either adults or peers, who are more competent than learners (Tzuriel \& Shamir, 2007). There have been some studies in the realm of mediation in general and peer-mediation in particular from previous decades. For instance, Tzuriel and Shamir (2007) tried to explore the effects of Peer Mediation with Young Children (PMYC) program on children's cognitive modifiability along with studying the effects of cognitive level of learners and mediators on their cognitive modifiability following the program. They randomly assigned a sample of 178 pupils to experimental and control groups. The mediators in the experimental group participated in the PMYC program, whereas the mediators in the control group received a substitute intervention aimed at emphasizing general conditions of peer interaction. The findings revealed that following the intervention, it's the mediators in the experimental group that showed higher level of analogy scores, as well as higher improvement on the dynamic analogy measure as compared with control mediators. The experimental learners also showed higher pre-to post-intervention achievements on the seriation problems as compared with control learners. They believed that "mediators in the experimental group had to cope with the incongruent cognitive level by facilitating their mediational approach and consequently enhancing the learner's performance" (p. 1).

Considering the literature on the mediated learning, the researchers came to the conclusion that few studies had capitalized on the role of teacher-mediation versus peermediation in improving grammar learning in Iranian EFL contexts. Therefore, this study is an attempt to fill in this gap and contribute to the existing literature on the role of mediation in learning English as a foreign language.

\section{METHOD}

\section{Research design}

To investigate the research questions, a quasi-experimental pretest, posttest research design was employed. "A typical experimental study usually uses comparisons or control groups to investigate research questions" (Mackey \& Gass, 2005, p. 146). Mackey and Gass (2005) categorized these kinds of studies as "between-groups design" in which one of the groups, i.e., the control group, receives no experimental treatment. 
In this study mediation is the independent variable that took place at two levels of teacher-mediation and peer-mediation and the dependent variable is the learning of passive/active voice sentences.

\section{Sampling and participants}

In order to explore the potential effect(s) of teacher and peer-mediation on grammar learning, a DA intervention approach was utilized. Although, based on the standards and placement test of the institute under study, the learners were considered as homogeneous and had the same L2 proficiency, the researcher administered Oxford Proficiency Test (OPT) to ensure the homogeneity. After the results of OPT, 45 male pre-intermediate students of English within the age range of 14-19, who were learning English at one of the private language institutes in Khoy, Iran, were selected from among 68 EFL learners based on one standard deviation (SD) above and below the mean on OPT. After this phase, the learners were assigned to three groups i.e., experimental group (A), experimental group (B), and control group. They were all natives of Khoy, and their mother tongue was Azerbaijani Turkish.

\section{Instruments}

The instruments included: 1) Oxford Placement Test, 2) pretest, 3) immediate and delayed posttests.

\section{1. $O P T$}

At the onset of the study, OPT was used in order to homogenize the participants' level of language proficiency. The questions of the mentioned test were taken from 'Oxford University Press and The University of Cambridge Local Examinations Syndicate' by UCLES (2001). The test has 60 items in the form of multiple-choice questions. The items are related to grammar, vocabulary and pronunciation mostly and students' general English ability is estimated through these sub-skills. The criterion for learners' homogeneity was their scores based on one SD above and below the mean. Allotted time to answer the questions was 60 minutes.

\section{Pretest \& Posttests}

The second instrument, in the current study, was a pretest to check the EFL learners' knowledge of active/passive voice. The same test, which was used for pretest, was also utilized for Immediate and delayed posttests in order to ensure comparability. In this study, the focus was on grammar learning and the textbook at the institute under study contains different grammatical points. Based on the experience of the researcher as a teacher and based on the content of the textbook, the tests were designed from among the standard tests of the institute. The total number of items on the test was 40 and the allotted time for test was 45 minutes. Considering the important role of validity, the test had been expert-judged by three experts in the assessment board of the institute. The panel of experts reported acceptable validity. The total score was considered 20 and the reliability of the scale was calculated through Cronbach's $\alpha$ to be 0.84 . 


\section{Procedure}

Two weeks before the beginning of the study, students were homogenized based on the scores of OPT, which is designed to test the pre-intermediate to intermediate learners' general language proficiency. The criterion for homogeneity of the learners was their scores based on one SD above and below the mean. After this phase and in order to investigate any possible impacts of the two mediation options, the 45 homogenized learners, from among the total of 68 EFL learners, were divided into three groups. The first group constituted the control group of the study and the two others formed the experimental groups i.e., the experimental groups (A) and experimental group (B). In the first experimental group, the researcher mediated the learners and, in the next experimental group, it was the learners themselves who mediated and interacted with each other, of course, after being well informed about the nature of mediation by the researcher. And the control group received no experimental mediation.

After homogenizing the learners, they were pretested by a grammar pretest as explained above in a different session before the treatment. The time limit for the pretest was 45 minutes. One session after the pretest, the instructor in the control group taught active/passive voice in the form of explicit grammar teaching. The learners were asked to use statements containing verbs and adjectives followed by active and passive voice according to the instructions given to them. The procedure for the control group included explanations regarding grammar in the target form under study at the beginning of the class. Also, different tasks like reading comprehension texts, role play, fill in the blanks and free composition were presented to the learners in order to elicit their knowledge in using active/passive voice. After two sessions of instruction and practice, in the third session, the students were given the immediate posttest, but without any mediation or any other form of assistance; in other words, the test was administered through non-dynamic procedure, which is also known as traditional or static approach. Four weeks after the immediate posttest, students in the control group took the delayed posttest with no mediation or scaffolding from the researcher.

The same process was carried out in teacher mediation group as the experimental group (A) with some differences. Very similar to the control group, the learners in teacher mediation group took the pretest and were taught active/passive voice sentences during two sessions and in the third session, immediate posttest was given to this group, but this time the researcher mediated the learners during the test. Indeed, the treatment was teacher's active engagement with the students during the test in that the researcher provided the learners with necessary explanations, suggestions, hints, leading questions, examples in a flexible and dialogic interaction. When necessary, learners along with the researcher resorted to their L1 during the mediation stage i.e., DA intervention or what Kozulin and Grab (2001) refer to as the teach stage. Four weeks after the immediate posttest, the learners in the teacher mediation group took the delayed posttest with the assistance of the researcher.

The third group that is the experimental group (B) received the same process as with the experimental group (A) and the control group with a slight difference. In this group, it was not the researcher who mediated the learners during the immediate and delayed 
posttests, rather it was the students themselves who mediated each other using required explanations, suggestions, hints, leading questions, examples in English or in their L1 when necessary. In short, all the processes that happened in three separate sessions in the experimental group (A) happened in the experimental group (B) as well.

\section{Data analysis}

To find answers to the research questions that investigated the existence of any significant difference in the relative effects of teacher-mediation versus peer-mediation on the performance of pre-intermediate learners in the use of target forms (active vs. passive voice) in the short and long-run, One-Way ANOVA test was run. Descriptive statistics and the relevant tables and figure are presented below.

\section{FINDINGS}

The first null hypothesis claimed that "There is no significant difference in the relative effects of teacher-mediation and peer-mediation on pre-intermediate English learners' use of target forms (active vs. passive voices) in the short-run". In order to test the hypothesis, One-way ANOVA was run. The number of the participants $(\mathrm{N})$, means (M) and SD of scores for each group are available in Table1.

Table1

Descriptive Statistics of Groups in the Short-run

\begin{tabular}{llllllll}
\hline & $\mathrm{N}$ & Min & Max & Mean & \multicolumn{2}{c}{ Std. Deviation } & Variance \\
\cline { 2 - 7 } & Statistic & Statistic & Statistic & Statistic & Std. Error & Statistic & Statistic \\
\hline Pretest Control & 15 & 2.00 & 9.00 & 5.9000 & .48068 & 2.14966 & 4.621 \\
Teacher Mediation & 15 & 2.00 & 9.00 & 6.0500 & .47281 & 2.11449 & 4.471 \\
Peer Mediation & 15 & 2.00 & 9.00 & 5.9000 & .46960 & 2.10013 & 4.411 \\
\hline Immediate Posttest & & & & & & & \\
Control & 15 & 5.00 & 11.00 & 7.7000 & .44780 & 2.00263 & 4.011 \\
Teacher Mediation & 15 & 14.00 & 19.00 & 16.4000 & .33561 & 1.50088 & 2.253 \\
Peer Mediation & 15 & 7.00 & 12.00 & 9.2000 & .33717 & 1.50787 & 2.274 \\
\hline Delayed-Pretest & & & & & & & \\
Control & 15 & 4.00 & 10.00 & 7.0000 & .41675 & 1.86378 & 3.474 \\
Teacher Mediation & 15 & 12.00 & 17.00 & 14.0000 & .35541 & 1.58944 & 2.526 \\
Peer Mediation & 15 & 5.00 & 11.00 & 7.9000 & .39670 & 1.77408 & 3.147 \\
\hline
\end{tabular}

As Table1 shows, the means of groups are pretty the same on pretest, but they are different on the immediate and delayed posttests. Then, it can be concluded that the learners were the same before the treatment but they were different after the treatment. 
Table 2

Tests of Normality for the Pretest, Immediate and Delayed Posttests

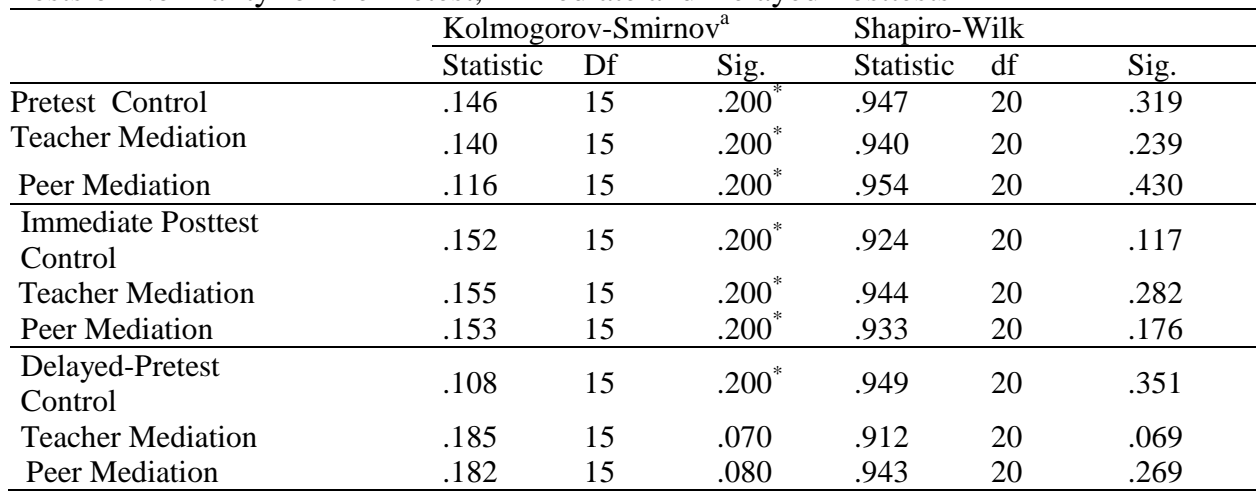

As all the significance levels are greater than 0.05 , it can be concluded that the scores are normally distributed. Therefore, parametric statistics can be utilized. There is a need for running One-way ANOVA to investigate the significance of the differences among the three groups. However, before running One-Way ANOVA, a test of homogeneity of variances, as an assumption to be met, needed to be ensured. The result is illustrated in Table 3 .

Table 3

Test of Homogeneity of Variances

\begin{tabular}{llll}
\hline Levene Statistic & df1 & df2 & Sig. \\
\hline 2.003 & 2 & 57 & .144 \\
\hline
\end{tabular}

As Table 3 shows, since the $p$-value (.144) is greater than the significance level .05 , the assumption of the homogeneity of variances is also met. Thus, ANOVA can be conducted on pretest and immediate posttest scores. Table 4 includes the results of ANOVA in the short-run.

Table 4

Results of ANOVA from pretest to immediate posttest

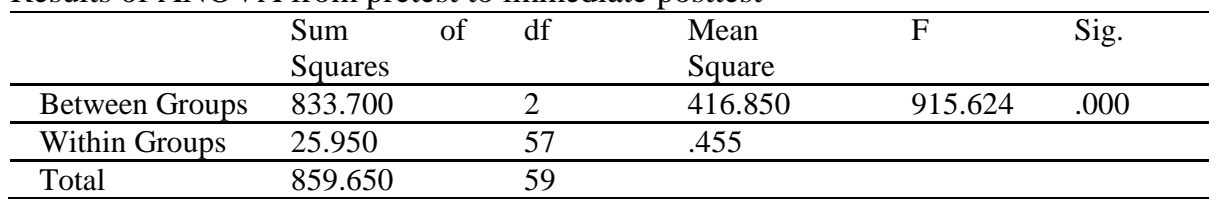

Since the $p$-value is $.000 \leq .0 .05$, it can be said that the groups are heterogeneous, $\mathrm{F}(2$, $57)=.915 .6, p=.000$. As stated, a statistically significant deference was found between the groups; therefore, in the short-term, the researcher, in order to find out where this difference lay, needed to run a post-hoc test. Table 5 shows the results of the post-hoc test. 
Table 5

Results of the Post Hoc Test in the short-run

\begin{tabular}{|c|c|c|c|c|c|c|}
\hline \multirow[t]{3}{*}{ (I) Group } & \multirow[t]{3}{*}{ (J) Group } & \multirow{3}{*}{$\begin{array}{l}\text { Mean } \\
\text { Differen } \\
\text { ce }(\mathrm{I}-\mathrm{J})\end{array}$} & \multirow{3}{*}{$\begin{array}{l}\text { Std. } \\
\text { Error }\end{array}$} & \multirow[t]{3}{*}{ Sig. } & $\begin{array}{l}95 \% \\
\text { Interval }\end{array}$ & Confidence \\
\hline & & & & & Lower & Upper \\
\hline & & & & & Bound & Bound \\
\hline \multirow[t]{3}{*}{ Control group } & Teacher & - & .213 & .000 & -9.0635 & -8.0365 \\
\hline & Mediation group & $8.55000^{*}$ & 37 & & & \\
\hline & $\begin{array}{l}\text { Peer } \\
\text { group }\end{array}$ & $-\overline{1.50000^{*}}$ & $\begin{array}{l}.213 \\
37\end{array}$ & .000 & -2.0135 & -.9865 \\
\hline \multirow{2}{*}{$\begin{array}{l}\text { Teacher } \\
\text { Mediation } \\
\text { group }\end{array}$} & Control group & $8.55000^{*}$ & $\begin{array}{l}.213 \\
37 \\
\end{array}$ & .000 & 8.0365 & 9.0635 \\
\hline & $\begin{array}{ll}\begin{array}{l}\text { Peer } \\
\text { group }\end{array} & \text { Mediation } \\
\end{array}$ & $7.05000^{*}$ & $\begin{array}{l}.213 \\
37 \\
\end{array}$ & .000 & 6.5365 & 7.5635 \\
\hline \multirow[t]{2}{*}{$\begin{array}{l}\text { Peer Mediation } \\
\text { group }\end{array}$} & Control group & $1.50000^{*}$ & $\begin{array}{l}.213 \\
37 \\
\end{array}$ & .000 & .9865 & 2.0135 \\
\hline & $\begin{array}{l}\text { Teacher } \\
\text { Mediation group }\end{array}$ & $-7.05000^{*}$ & $\begin{array}{l}.213 \\
37\end{array}$ & .000 & -7.5635 & -6.5365 \\
\hline
\end{tabular}

Based on Table 5, there was a significant difference between the teacher mediation and peer mediation and peer mediation and control group. Therefore, it can be concluded that the experimental group (A) performed better than the experimental group (B) and control group in grammar learning from pretest to immediate posttest in the short-run. Thus, the first hypothesis of the study "There is no significant difference in the relative effects of teacher-mediation and peer-mediation on pre-intermediate English learners' use of target forms (active vs. passive voices) in the short-run", is disapproved, figure1 clarifies the results of treatment in the short-run.

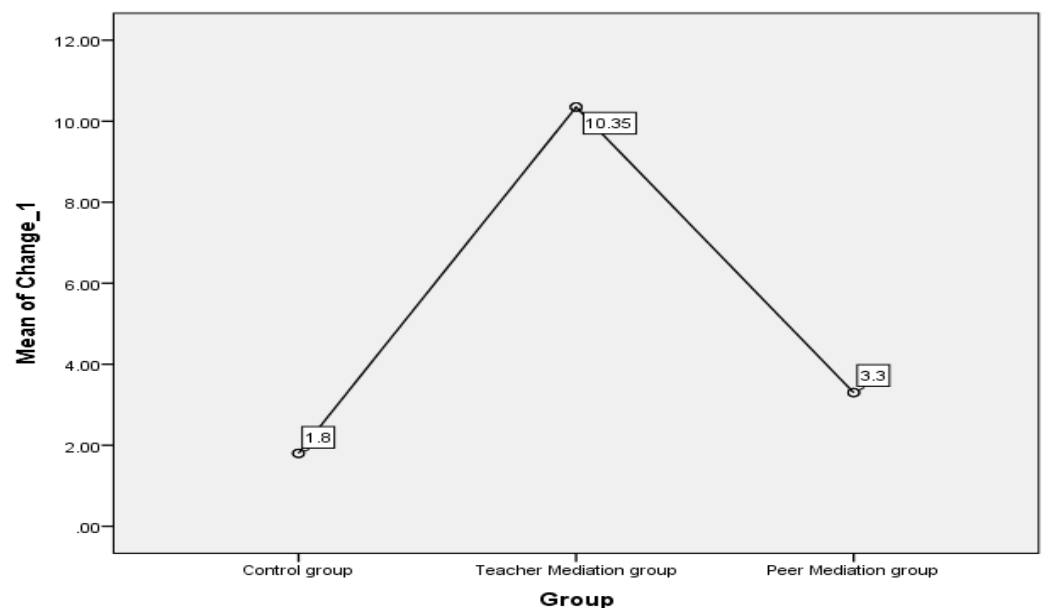

Figure 1

The results of group's performance in the short-run 


\section{Hypothesis Two}

The present study also aimed at discovering the role of mediation on grammar retention in the long-run. The related analyses are carried out to investigate the second hypothesis of the current study, that is, "There is not any significant difference in the relative effects of teacher-mediation and peer-mediation on pre-intermediate English learners' use of target forms (active vs. passive voices) in the long-run?".

Table 6 shows the results of ANOVA from pretest to delayed posttest.

Table 6

Results of ANOVA from pretest to delayed posttest

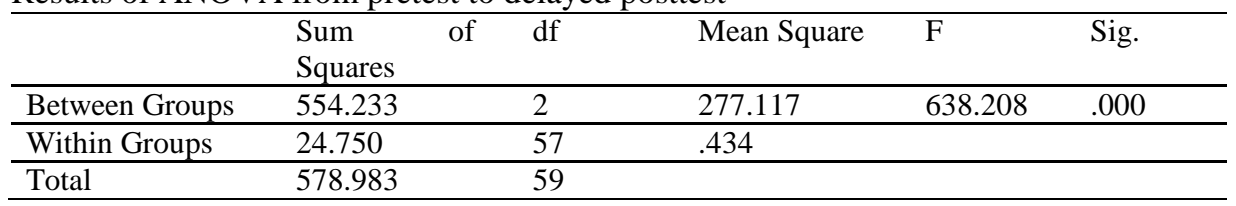

Since the $p$-value is $.000 \leq .0 .05$, it can be said that the groups are heterogeneous, $\mathrm{F}(2$, $57)=.638 .2, p=.000$. As stated, a statistically significant deference was found between the groups in the long-run, the researcher, then, needed to compute a post-hoc test (Tukey or Schefe post-hoc tests). Table 7 shows the results of the post-hoc test in the long-run.

Table 7

Results of Post Hoc Test in the long-run

\begin{tabular}{|c|c|c|c|c|c|c|}
\hline \multirow[t]{3}{*}{ (I) Group } & \multirow[t]{3}{*}{ (J) Group } & \multirow{3}{*}{$\begin{array}{l}\text { Mean } \\
\text { Differen } \\
\text { ce (I-J) }\end{array}$} & \multirow[t]{3}{*}{$\begin{array}{l}\text { Std. } \\
\text { Error }\end{array}$} & \multirow[t]{3}{*}{ Sig. } & $\begin{array}{l}95 \% \\
\text { Interval }\end{array}$ & Confidence \\
\hline & & & & & Lower & Upper \\
\hline & & & & & Bound & Bound \\
\hline \multirow{3}{*}{ Control group } & Teacher & - & .208 & .000 & $\begin{array}{l}-7.3514 \\
\end{array}$ & -6.3486 \\
\hline & Mediation group & $6.85000^{*}$ & 38 & & & \\
\hline & $\begin{array}{ll}\begin{array}{l}\text { Peer } \\
\text { group }\end{array} & \text { Mediation } \\
\end{array}$ & $-.90000^{*}$ & $\begin{array}{l}.208 \\
38 \\
\end{array}$ & .000 & -1.4014 & -.3986 \\
\hline \multirow{2}{*}{$\begin{array}{l}\text { Teacher } \\
\text { Mediation group }\end{array}$} & Control group & $6.85000^{*}$ & $\begin{array}{l}.208 \\
38\end{array}$ & .000 & 6.3486 & 7.3514 \\
\hline & $\begin{array}{ll}\begin{array}{l}\text { Peer } \\
\text { group }\end{array} & \text { Mediation } \\
\end{array}$ & $5.95000^{*}$ & $\begin{array}{l}50 \\
.208 \\
38\end{array}$ & .000 & 5.4486 & 6.4514 \\
\hline \multirow[t]{2}{*}{$\begin{array}{ll}\text { Peer } & \text { Mediation } \\
\text { group } & \end{array}$} & Control group & $.90000^{*}$ & $\begin{array}{l}.208 \\
38 \\
\end{array}$ & .000 & .3986 & 1.4014 \\
\hline & $\begin{array}{l}\text { Teacher } \\
\text { Mediation group }\end{array}$ & $5.95000^{*}$ & $\begin{array}{l}.208 \\
38\end{array}$ & .000 & -6.4514 & -5.4486 \\
\hline
\end{tabular}

Based on Table 7, there was a significant difference between the experimental group (A) and experimental group (B) and the control group in the long-run to the effect that the teacher mediation group outperformed the peer mediation and control group in grammar learning from pretest to delayed posttest in the long-run. It means, grammar retention was high in the teacher mediation group in comparison with both the peer mediation and control group. Therefore, the second hypothesis, "There is not any significant difference 
in the relative effects of teacher-mediation and peer-mediation on pre-intermediate English learners' use of target forms (active vs. passive voices) in the long-run?" is disapproved. Figure 2 clarifies the results of grammar retention of mediation strategies in the long-run.

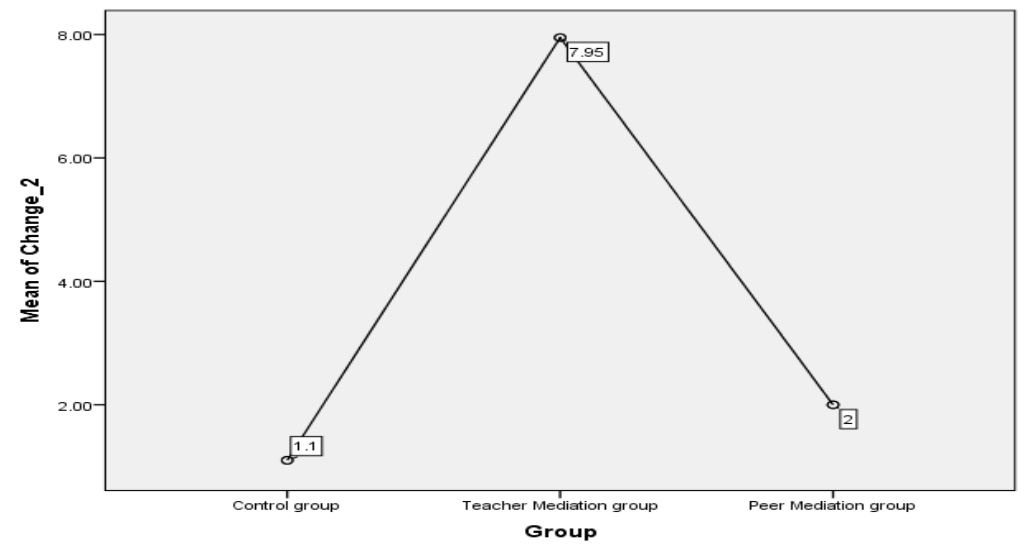

Figure 2

The results of group's performance in long-term

\section{DISCUSSION}

The purpose of the current study was to investigate the effectiveness of mediation techniques (teacher-mediation \& peer-mediation) on grammar (active vs. passive voice) learning of EFL learners at pre-intermediate level. The first research question attempted to explore the effect of teacher-mediation and peer-mediation, as SCT strategies, and explicit/traditional grammar instruction on Iranian pre-intermediate EFL learners' grammar learning. The results revealed that teacher-mediation improved adult EFL learners' grammar learning in the short and long-run. In other words, the results are in favor of using teacher-mediation strategy in teaching target forms. The reason for the effectiveness of teacher-mediation in adult learners' classrooms may be because of the fact that teacher-mediation, as a scaffolding tool, removes anxiety of the students and, consequently, increases their performance in learning a sub-skill like grammar. Furthermore, the results of the post-hoc analysis indicated that the effects of peermediation and conventional grammar instruction were not statistically significant in grammar learning of adult EFL learners. As a result, the first null hypothesis, which claimed "There is no significant difference in the relative effects of teacher-mediation and peer-mediation on pre-intermediate English learners' use of target forms (active vs. passive voices) in the short-run" was disapproved.

The results divulged that peer-mediation was not effective; the reason for the ineffectiveness of this strategy can be the difficulty in performing this technique for lowlevel learners of this study in a context like Iran. It is a strategy that some learners are not familiar with, as we saw in Hidri's case. Indeed, they are reluctant to use it, perhaps due to the personality factors such as pride and arrogance or mainly shyness. That said, 
it is argued that peer-assessment can be controversial in that it can yield unreliable results caused by student assessors' lack of experience, and often produces undifferentiated marks (Kennedy, 2005). As Clark, Davies and Skeers (2005) argue, the labor-intensive processes that the subject coordinators have to administer are problematic; another account for the ineffectiveness of peer-mediation could probably be its uncomfortable nature due to individual differences. This justification has been approved by different studies such as Freeman and McKenzie (2002), who claimed that traditional peer-mediation creates an uncomfortable context and some students seem to be dishonest and unfair during traditional peer-mediation when compared with online peer-mediation. However, despite its mentioned shortcomings, not only do students who are involved in the process benefit from it, but also it has considerable outcomes for peer mediators themselves and as Lane and McWhirter, 1992; Roush and Hall, 1993; Stomfay-Stitz, 1994, (cited in Humphries, 1999) point out, student mediators generally are capable of expressing problems, developing skills required to solve those problems, developing better communication skills, and also having a more positive view of themselves.

The second research question addressed the effectiveness of teacher-mediation, peermediation, and traditional instruction in grammar learning and retention of preintermediate EFL learners in the long-run through a delayed posttest. The results indicated that in the long-run low-level learners did not forget the target forms taught through teacher-mediation. The reason for the effectiveness of teacher-mediation on grammar retention of EFL learners during testing can be that teacher-mediation testing might relieve the tension of the testing and pressure of instruction and create positive, effective and memorable memories which in turn can strengthen grammar retention; however, it can further be examined by interviews or think-aloud protocols. The other justification for the long-term effectiveness of teacher-mediation can be the effect that teacher-mediation had on social emotional learning (SEL) of the learners. SEL as a cognitive-affective concept focuses on assisting the individuals, especially low-level learners to gain knowledge about feelings and get along with others (Marion, 2011). There is a necessity of education to broaden teachers and students' understanding of one another in order to model practices that teach social, communicative, and problemsolving skills. Finally, it is assumed that teacher-mediation offers a positive way to break with the demotivating cycle of education in schools and language institutes. Demotivating cycle of education is when a pupil enters an educational setting like a class and may exhibit frustration, withdrawal, or more disruptive behavior, which in turn may result in more isolation.

Then, the second null hypothesis that claimed "There is no significant difference in the relative effects of teacher-mediation and peer-mediation on pre-intermediate English learners' use of target forms (active vs. passive voices) in the long-run" was disapproved. Regarding the ineffectiveness of peer-mediation, the findings of this study can be in keeping with Piaget (1970) and Dewey's (1902) constructivist approaches. According to the constructivist notions of Piaget and Dewey, children learn spontaneously when given opportunities to discover laws, concepts and operations by themselves. By contrast, regarding the effectiveness of teacher-mediation, both 
Vygotsky and Feuerstein hold that scientific concepts or any higher-order cognitive processes are better acquired by active intentional efforts from an experienced mediator.

The present research can also offer implications for EFL students in that, instead of the traditional methods of testing and instruction, they can try a mixture of different strategies like teacher or peer-mediation in their own learning experiences. It is generally believed that there is no "one-size-fits-all" method of instruction; therefore, teacher-student mediation may allow the teachers and learners to provide a safe way to identify the underlying causes of problematic issues like grammar. More specifically, the findings of this study can arouse both teachers and learners' interest in a dynamic approach, since there is a kind of interaction and cooperation between teachers and learners, which results in a class atmosphere in which learners may feel more secure and relaxed. Indeed, in a dynamic approach, assessment and instruction are pooled, the result of which would promote teaching and learning to a certain degree and testing would lose its daunting and threatening face.

\section{CONCLUSION}

As stated, the current study aimed at exploring the effect of two mediation techniques, that is, teacher-mediation and peer-mediation on grammar learning and retention at preintermediate level. The findings indicated that both in the short and long-run, teachermediation was more effective than peer-mediation and traditional method. The findings convey the idea that not all types of DA can be equally effective, as we observed in the present study in which teacher-mediation proved to improve the learning of passive/active voice both in the short and long-run. However, peer-mediation did not dramatically promote the performance of the participants on either the immediate or delayed posttests.

Nevertheless, the present study was subject to some limitations such as course length and the level of participants. Therefore, for future body of research, it is recommended that this study be replicated with a larger number of participants at different language proficiency levels to compare the results. The length of the course may be critical in gaining results; thus, a similar research can be conducted through a longer course of instruction to compare the results of the investigations. Investigation of other types of mediation can also be a rich area for future research in EFL contexts.

The implications of this study can be helpful for language teachers who can apply mediation to improve grammatical accuracy of their learners. They can also give special attention to the role of peer-mediation in terms of learners' level. Teacher trainers can also instruct teachers how to use scaffolding and mediation in their teaching practice, of course after priming them with the value and effectiveness of such methodology. Material designers can prepare materials that encourage teachers to apply mediation based on students' level of knowledge and individual differences. 


\section{REFERENCES}

Ableeva, R. (2008). The effects of dynamic assessment on L2 listening comprehension. In J. P. Lantolf and M. E. Poehner (Eds.), sociocultural theory and the teaching of second languages (pp. 57-86). London: Equinox.

Azabdaftari, B. (2015). A collection of English Papers on language and interdisciplinary studies. Tabriz University: Tabriz University Press.

Clark, N., Davies, P., \& Skeers, R. (2005). Self and peer assessment in software engineering projects. In Proceedings of the 7th Australasian conference on Computing Education. Newcastle, NSW.

Dewey, J. (1902). The child and the curriculum. Chicago: Chicago University Press.

Freeman, M., \& McKenzie, J. (2002). SPARK, a confidential web-based template for self and peer assessment of student teamwork: benefits of evaluating across different subjects. British Journal of Educational Technology, 33, 551-569.

Halliday, M. A. K. (1973). Explorations in the Functions of Language. London: Edward Arnold.

Haywood, H. C., \& Lidz, C. S. (2007). Dynamic Assessment in Practice: Clinical and Educational Applications. New York: Cambridge University Press.

Hidri, S. (2014). Developing and evaluating a dynamic assessment of listening comprehension in an EFL context. Language Testing in Asia, 4(4).

Humphries, T. L. (1999). Improving peer mediation programs: Student experiences and suggestions. Professional School Counselling, 3(1), 13-21.

Karpove, Y. (2008). Do all dynamic assessment techniques assess learning potential? Journal of Cognitive Education and Psychology, 7(3), 411-418.

Kennedy, G. J. (2005). Peer-assessment in Group Projects: Is it worth it? The Australasian Computing Education Conference. Newcastle, Australia.

Kozulin, A., \& Grab, E. (2001). Dynamic assessment of EFL text comprehension of at risk students. The 9th Conference of the European Association for Research on Learning and Instruction, August, Fribourg, Switzerland.

Lantolf, J. P. (2003) Intrapersonal communication and internalization in the second language classroom. In A.

Kozulin, V. S. Ageev, S. Miller \& B. Gindis, (eds.) Vygotsky's Theory of Education in Cultural Context. Cambridge: Cambridge University Press.

Lantolf, J. P., \& Thorne, S. L. (2006). Sociocultural theory and the genesis of second language development. Oxford: Oxford University Press.

Mackey, A., \& Gass, S. M. (2005). Second language research: Methodology and design. Mahwah, NJ: Erlbaum. 
Marion, M. (2011). Guidance of Young Children (8th ed.). Upper Saddle River, NJ: Pearson Education.

Murphy, R. (2008). Dynamic assessment precursors: Soviet ideology and Vygotsky. The Irish Journal of Psychology, 29(3-4), 193-233.

Piaget, J. (1970). Genetic epistemology. New York: Columbia University Press.

Poehner, M. E. (2008). Dynamic assessment: A Vygotskian approach to understanding and promoting second language development. Berlin: Springer Publisher.

Poehner, M. E., \& Lantolf, J. P. (2003). Dynamic Assessment of L2 Development: Bringing the Past into the Future. CALPER Working Paper Series, No. 1. The Pennsylvania State University, Center for Advanced Language Proficiency, Education and Research. Retrieved December 17, 2009 from http://www.equinoxjournals.com/ojs/index.php/JAL/artical/viewArticle/647.

Shamir, A. (2005). Mediational teaching style as a function of intervention for peer mediation among junior high school peers. Education and society, 23(2), 63-81.

Tzuriel, D. (1999). Parent-child mediated learning transactions as determinants of cognitive modifiability: Recent research and future directions. Genetic, Social, and General Psychology Monographs, 125, 109-156.

Tzuriel, D., \& Shamir, A. (2007). The effects of peer mediation with young children (PMYC) on children's cognitive modifiability. British Journal of Educational Psychology, 77 (1), 143-165.

Valsiner, J. (2001). Process structure of semiotic mediation in human development. Human Development, 44, 84-97.

Vygotsky, L. S. (1986). Thought and language (Rev. ed.). Cambridge, MA: MIT Press.

Williams, M., \& Burden, R. (1997). Psychology for language teachers: A social constructivist approach. Cambridge: Cambridge University Press. 